\title{
Understanding Responses to Materials and Colors in Interiors
}

\section{Begüm Ulusoy, ${ }^{\star}$ Nilgün Olguntürk}

Department of Interior Architecture and Environmental Design, Bilkent University Faculty of Art, Design and Architecture, Ankara, Turkey

Received 26 January 2016; revised 16 June 2016; accepted 20 June 2016

\begin{abstract}
This article investigates the free associations of materials and colors in the context of interior architecture. Materials and colors rarely appear alone in interiors; therefore, in the scope of this study, the researchers explored material pairs and color pairs in addition to single materials and single colors. To elicit free associations from these interior design elements, 192 randomly selected volunteers participated in an experiment using a group of material (fabric, timber, plasterboard) and color (red, green, white) models under controlled conditions. The results contribute to an increased understanding of the associations between the concepts of materials and colors in interiors. While, each model was associated with sensory descriptors, only some models were associated with symbolic or affective descriptors. Single materials were related to different descriptors in interiors on their own, but when they were paired they were associated with fewer affective descriptors. The results showed that color pairs were always associated with all types of descriptors with an exception of red and green color pair, which was not mentioned with affective descriptors. The study findings are expected to be beneficial for interior architects, architects, product designers and researchers who want to shape and investigate a user's experience of interiors. @ 2016 Wiley Periodicals, Inc. Col Res Appl, 42, 261-272, 2017; Published Online 9 July 2016 in Wiley Online Library (wileyonlinelibrary.com). DOI 10.1002/col.22072
\end{abstract}

Key words: design; color; material; free associations

\section{INTRODUCTION}

Seeing is the first human sense that dominates perception and knowledge. Visual abilities are developed before words; almost every person first sees and recognizes his

\footnotetext{
*Correspondence to: Begüm Ulusoy (e-mail: ulusoy@bilkent.edu.tr)
}

(C) 2016 Wiley Periodicals, Inc. or her environment and then defines each element of it according to what he or she sees. ${ }^{1}$ Words are taught by the family or the network, defined by their respective culture and society and are associated with objects, the environment, and the surroundings. Materials and colors, which are substantial characteristics of any environment, are associated with perceptional, emotional, and cognitive processes. Individuals with full visual ability see materials and colors and define their environments by them. The Stroop effect, which results in longer or shorter reaction time of reading or misreading words due to their color, ${ }^{2}$ is an example of the dominant influence that visual stimuli have on people's perception and knowledge. Wastiels et al. stated that people's overall perception is dominated by the visual sense in interiors. ${ }^{3}$ Language is related with vision (see Fig. 1) ${ }^{4}$ and people's associations between the two show how they perceive and experience interiors.

Materials and colors, as fundamental elements of interior architecture, also affect the user's perception. To explore the associations between these elements, the researchers embraced the User Conceptual Model, which "constitute an inventory of the meaning that a community of users have available, can easily acquire, and are likely to enact, given the possibilities that artifacts suggest" ${ }^{\prime 5}$ [p. 108]. This model "explains experiences that users bring to artifacts they intend to use" [p. 105]. Su and Yang stated that "basic emotions are original perceptions of products that can be expressed when stakeholders interact with product" ${ }^{6}[\mathrm{p}$. 109]. Considering the user or stakeholder as a focus of design decisions, the designer should obtain proper knowledge about the associations of design elements. Identifying any design with its stakeholder also calls for linguistic elements; because users define artifacts with words (see Fig. 2). Therefore, instead of asking directly about the meanings and emotions elicited by materials and colors, the researchers in the current study utilized the free-association method for participants encountering artifacts. Free association as a method of this study was preferred because it elicits more diverse results than other methods such as interviews, 


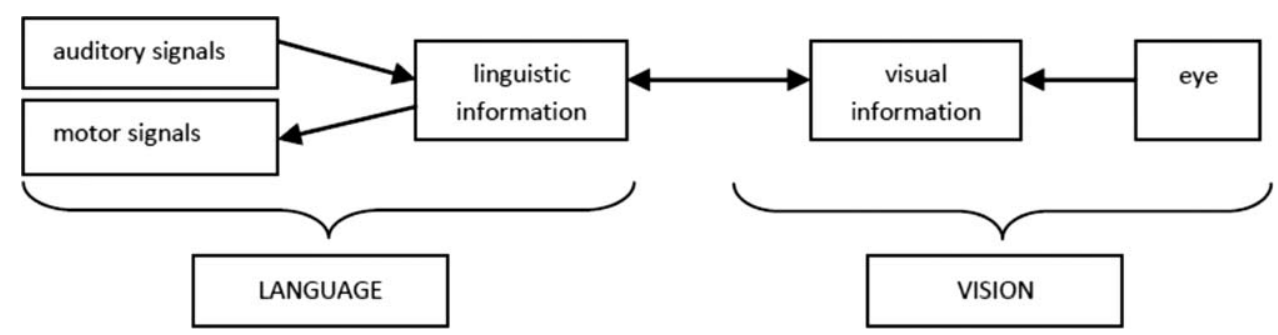

Fig. 1. The relation between language and vision according to ref. 4 .

semantic scales, questionnaires, etc. In addition, it probes initial reactions without unpredictable effects of other methods, for instance, a direct question might bias an answer.

According to Ludueña et al., free association is "a task that requires a subject to express the first word to come to their mind when presented with a certain cue"7 [p. 195]. Fenko et al. noted that, "language is one of the core components of any culture" and is "closely related to thought" $"$ [p. 3315]. Rompay and Ludden articulated that "designers communicate affective meaning through their design" in the study, which they elaborated the experience of product $^{9}$ [p. 1]. One view of explaining product experience consists of three components: aesthetic experience, experience of meaning and emotional experience $^{10}$ which might be corresponded to sensory, symbolic, and affective descriptors respectively, that were defined by the study of Fenko et $a l^{8}$ These product design studies could be adopted to interior design to inquire an experience of interior design elements in the context of associations. When people define their experiences with products, they use adjectives divided into three categories: sensory, symbolic, and affective descriptors. ${ }^{8}$ In the previous study, sensory descriptors are defined using the five senses: visual, tactile, auditory, olfactory, and gustatory; using descriptors such as color, rough, loud, bitter, etc. ${ }^{8}$ Symbolic descriptors include words such as luxurious, modern, and complex, and affective descriptors include funny, exiting, and cute. ${ }^{8}$ In this study, sensory descriptors are associated with physical characteristics experienced through the five senses, for this study, the concentration is on the sensory descriptor of vision, symbolic descriptors are related to the design's symbolic meanings, and affective descriptors are associated with emotions.

Materials and colors do not usually appear alone in interiors. It is quite difficult to find an interior that consists of the same type of material and color. Although the meanings and associations of single materials and single colors have been studied, no research until now has explored the free associations of material pairs and color pairs in interiors. There is a lack of knowledge in the literature about how occupants/users define material pairs and color pairs verbally and about their first impressions. For this reason, in this study, the researchers aimed to elicit free associations of these concepts. They conducted an experimental study on materials, colors, material pairs, and color pairs in interiors. The researchers prepared controlled experiment conditions with a group of models that presented a corner of an ordinary interior, with no function assigned. To examine these free associations of materials and colors in interiors, the researchers asked two open-ended questions to 192 participants. The questions aimed to determine what associations the models inspired.

\section{Materials in Interiors}

Materials are important design decision elements in interiors. "Understanding how materials are selected, composed, and assembled is an essential skill for interior design" 11 [p. 6]. Su and Yang indicated that human needs

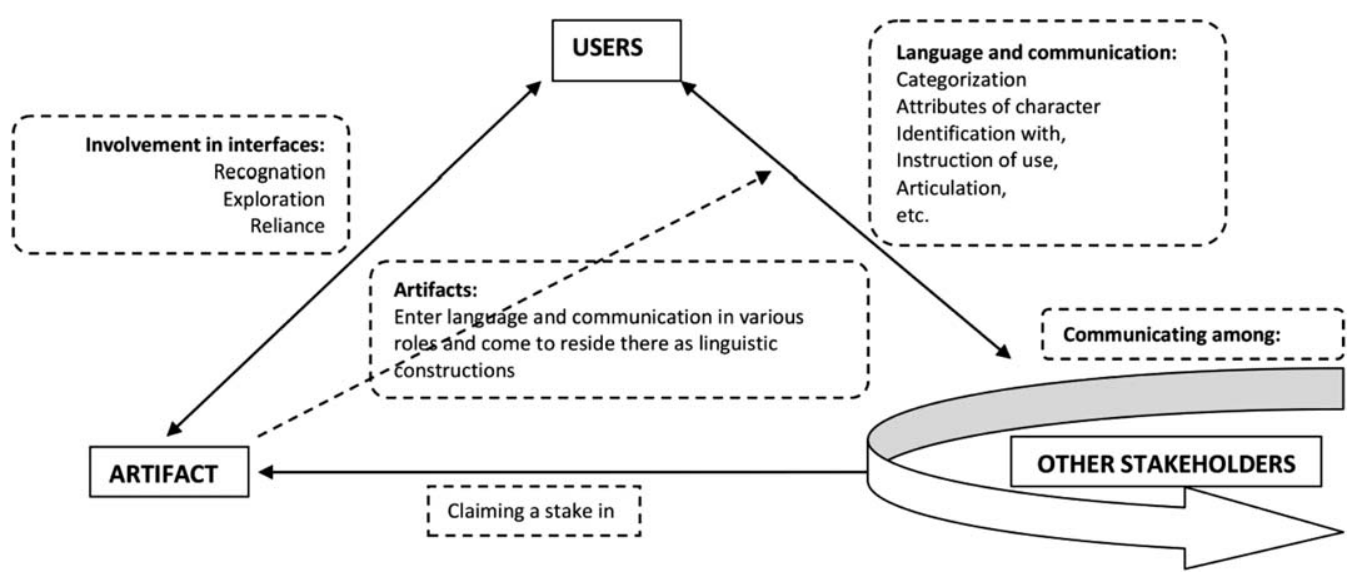

Fig. 2. Artifacts in language and communication according to ref. 5 . 
TABLE I. Emotional associations of colors.

\begin{tabular}{lll}
\hline \multirow{2}{*}{$\begin{array}{l}\text { Color } \\
\text { Chromatic Colors }\end{array}$} & \multicolumn{1}{c}{ Emotion } \\
\cline { 2 - 3 } Red & $\begin{array}{c}\text { Positive emotions } \\
\text { Happiness, surprise, energetic, powerfulness, } \\
\text { enjoyment, passionate } \\
\text { Happiness, calmness, peacefulness, hopefulness, } \\
\text { relaxation, comfort, modernism } \\
\text { Surprise }\end{array}$ & $\begin{array}{l}\text { Sadness, anger, fear } \\
\text { White }\end{array}$ \\
\hline
\end{tabular}

Adapted from Ref. 27.

have changed from developments throughout history, moving from basic survival needs to more complicated ones. ${ }^{6}$ For instance, materials that merely satisfy the basic need to survive are no longer successful or sufficient for most people in developed societies today. Therefore, designers should carefully consider these needs and explore the material experience of the artifacts and interiors they created. Some material properties, such as thermal effusivity, ${ }^{3}$ roughness, ${ }^{12}$ and sliding friction ${ }^{13}$ affect the perception of designs and their existence contributes to how interiors are perceived. Hekkert and Karana posited that materials are ascribed "universal" and "learned" meanings ${ }^{14}$ [p. 8-9]. "Universal meanings" would be related to subtle characteristics that would be similar across cultures. For example, the tactile sensation of timber is warm regardless of culture, and thus it is regarded as inviting and cosy, whereas soft materials are associated with being alive. ${ }^{14}$ Karana et al. explored the same concept in the context of product design. ${ }^{15}$ Their findings show that timber and natural materials are associated with nostalgia. "Learned meanings," however, vary among societies and they are more related to cultural background. For instance, in another study, Karana and Hekkert reported that compared with Dutch participants, Chinese participants appraised plastic products as being more elegant than metal ones. ${ }^{16}$

Many researchers have explored material experiences and their effects on design. ${ }^{17-19}$ In the context of interior design, Wastiels and Wouters determined that the experiential quality of the concept is crucial, but surprisingly, there is not a vast amount of knowledge. ${ }^{19}$ They concentrated on the material selection process for buildings in different design stages. Brown and Farrelly demonstrated that materials have social, cultural, and personal aspects, which affect the experience in interiors. ${ }^{11}$ They stated that people associated some materials with specific meanings and emotions; for example, in Europe, stone is associated with power, wealth, and prestige because it is expensive. Due to its texture and color, timber is a warm material in interiors, ${ }^{20}$ and Gagg, noted that timber was one of the initial interior design materials, ever since humans first devised shelters, therefore it has been associated with home. ${ }^{21}$

\section{Colors in Interiors}

Color is a substantial visual bond that constitutes emotional, sensorial, and physical relations between people and their environment. Colors affect people's perceptions and behaviors by their associations. Some color associations are universal: red-orange-yellow colors are considered warm and green-blue-purple colors are considered cool. ${ }^{22}$ However, other color associations are cultural as learned meanings of materials: white symbolizes purity in Western culture, but mourning in India. ${ }^{23}$ Hutchings reported that "green above all colors has especial significance both in the UK and Ireland" ${ }^{24}$ [p. 57]. The folkloric study reported that, in Britain and Ireland, wearing green is associated with unluckiness and that this belief has been imported to North America through immigration. However, green is significantly important and has positive associations for both cultures as well: life, springtime, growth for Britain, and St. Patrick and the shamrock for Ireland. ${ }^{24}$ Product design studies elicited some associations of colors for product scale. For instance, brand colors are designed according to the associations that colors carry, such as high quality and love associated with red and sincerity, warmth, and honesty associated with green, and light colors, especially white, are apparently used to package cheaper products produced for low classes. ${ }^{25}$ Moreover, products carry these color associations as well. $\mathrm{Na}$ and Suk investigated emotional characteristics of white, in the context of product design and concluded that white was assessed as the most elegant color when it is compared with other colors. ${ }^{26}$ Findings of two studies contradicted about the meaning of white. This contradiction might be result of different contexts: product colors ${ }^{26}$ and brand colors. ${ }^{25}$ More studies are needed to have a better idea on the meaning of white.

Color not only has impacts on psychology and physiology of human beings, ${ }^{27}$ but also affects the perception of interiors. ${ }^{28}$ Helvacioğlu prepared a list of emotions of colors that were studied by different researchers (see Table I). ${ }^{27}$ In this study, Helvacioğlu utilized emotive faces and asked participants to match the faces with the presented interior of a virtual ordinary living room (Second Life and CamStudio 2.6 Beta programs were used to create the room). ${ }^{27}$ Among other results, the study concluded that red walls were mostly associated with disgust and happiness, and green walls were mostly associated with neutral and happiness. Although both red and green are able to induce happiness in a living room, red seems to be a slightly riskier color as it can induce disgust in some of the population. 


\begin{tabular}{|c|c|c|c|}
\hline \multicolumn{2}{|c|}{ Single and Paired Materials } & \multicolumn{2}{|c|}{ Single and Paired Colour } \\
\hline $\begin{array}{l}\text { Fabric } \\
\text { (S 3070-Y90R) }\end{array}$ & $\otimes$ & $\begin{array}{l}\text { Red } \\
\text { (S 3070Y-90R) }\end{array}$ & \\
\hline $\begin{array}{l}\text { Timber } \\
\text { (S 3070-Y90R) }\end{array}$ & & $\begin{array}{l}\text { Green } \\
\text { S 5040B-80G }\end{array}$ & \\
\hline $\begin{array}{l}\text { Plasterboard } \\
\text { (S 3070-Y90R) }\end{array}$ & & $\begin{array}{l}\text { White } \\
\text { S 0510R-50B }\end{array}$ & \\
\hline $\begin{array}{l}\text { Fabric+Timber } \\
\text { (S 3070-Y90R) }\end{array}$ & & Red+White & \\
\hline $\begin{array}{l}\text { Timber+Fabric } \\
\text { (S 3070-Y90R) }\end{array}$ & & White+Red & \\
\hline $\begin{array}{l}\text { Fabric+Plasterboard } \\
\text { (S 3070-Y90R) }\end{array}$ & & Red+Green & \\
\hline $\begin{array}{l}\text { Plasterboard+Fabric } \\
\text { (S 3070-Y90R) }\end{array}$ & & Green+Red & \\
\hline $\begin{array}{l}\text { Timber+Plasterboard } \\
\text { (S 3070-Y90R) }\end{array}$ & Py. & Green+White & \\
\hline $\begin{array}{l}\text { Plasterboard+Timber } \\
\text { (S 3070-Y90R) }\end{array}$ & $\Delta$ & White+Green & \\
\hline
\end{tabular}

Fig. 3. Single and paired materials and colors.

\section{METHOD}

\section{Present Study}

The main aim of this study is to investigate the free associations of materials and colors in interiors. As materials and colors are rarely viewed in isolation, both single and paired materials and colors were used for this investigation. the researchers used three material pairs with one fixed color (red, with the S 3070-Y90R NCS code) as well as three color pairs with one fixed material $(100 \%$ cotton fabric). They paired three single materials in order to create three material pair and three single colors in order to create three color pairs (see Fig. 3). These single and paired materials and colors were presented with models which were designed by the researchers (see Fig. 4). The same experimental conditions were used with the same methodology for all the material models and the

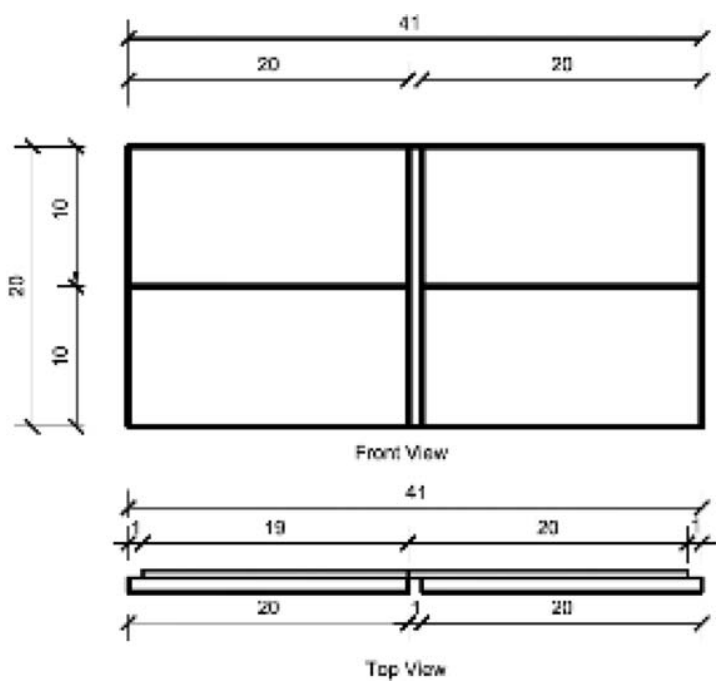

Fig. 4. Dimensions of the model. color models. Each participant viewed only one model in order to ensure accuracy of the results with unbiased free associations and to overcome the order effect.

\section{Participants}

The study was conducted with 192 participants in Belfast, Northern Ireland, UK. The participants were chosen and asked randomly while they were walking down the street and then participated voluntarily and received no payment or other incentives. The average age of the sample group was 29 (between 18 and 70 years of age, balanced genders). The researchers informed the participants that they would be participating in an experiment about materials and colors as a part of a $\mathrm{PhD}$ study. No further information was given.

\section{Experimental Setting}

The researchers used, in the experiment setting, a box (inside dimensions: $40 \mathrm{~cm}$ height, $50 \mathrm{~cm}$ width, and $50 \mathrm{~cm}$ depth) (see Fig. 5), a fluorescent lamp [Philips TLD 90 Graphica 18W 965-59 cm (MASTER)] which satisfies the requirements of accurate color vision conditions, and measurement equipment (an NCS 96 Atlas, a Konica Minolta Illuminance Meter T-10A, a temperature gauge and a digital thermometer with Samsung Galaxy S4 sensors) in a room with controlled conditions (see Fig. 6).

The researchers constructed the experimental box to exhibit the models under controlled laboratory conditions. They covered the inside of the box with gray (NCS color code: S-3000) cardboard, which is recommended as a masking color by the NCS 96 Atlas. The box was placed on a table $90 \mathrm{~cm}$ high and participants sat on a fixed chair, at a distance of $50 \mathrm{~cm}$ from the front of the box. One lamp [Philips TL-D 90 Graphica 18W 965-59 cm (MASTER)] was fixed inside the box to the center of the top surface, which ensured excellent color rendering with 90 to $100 \mathrm{Ra}$ and provided a homogenous illuminance

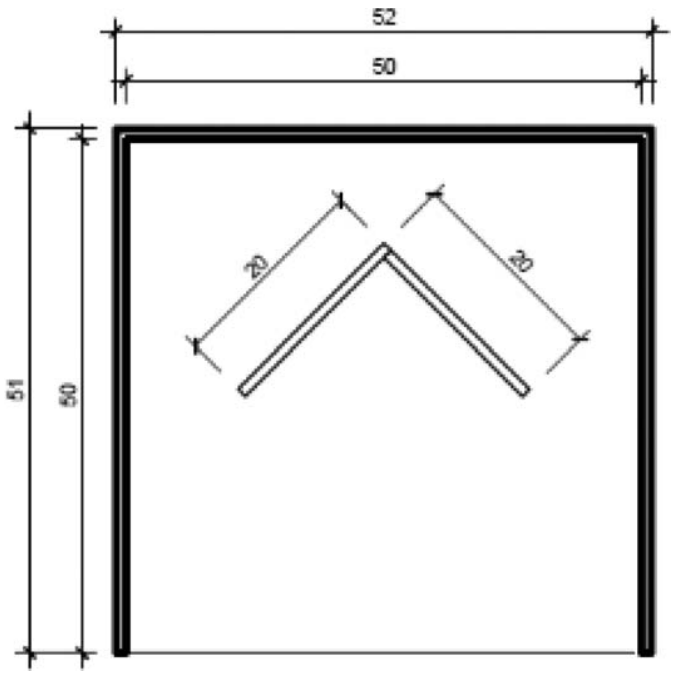

Fig. 5. Inside of the experiment box as a sectional top view. 


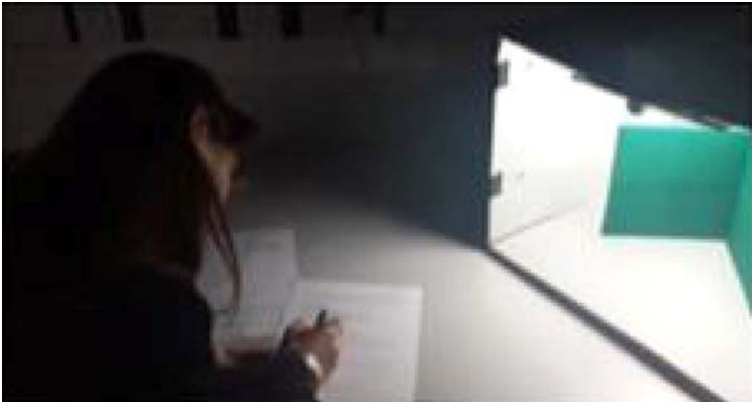

Fig. 6. Experiment room.

level. It provided approximately 400 lux with $6500 \mathrm{~K}$ color temperature, which are suitable lighting conditions in an ordinary space for reading and working activities as suggested by the IESNA. ${ }^{29}$ The experiment room (with approximately 400 lux) was illuminated by two fluorescent lamps which were turned off before the experiment started. Natural light, which cannot be controlled, was blocked with black cardboards and curtains. The researchers used a Konica Minolta Illuminance Meter T-10A to measure the illuminance level, and a temperature gauge and a digital thermometer to measure the room temperature. Heating equipment was used to adjust the indoor climate conditions when necessary. The constant room temperature was kept at $22^{\circ} \mathrm{C}$ as recommended by Neufert. ${ }^{30}$

\section{Models}

Each material and color was prepared with the other two separately to ensure pairs. To eliminate any effect of material/color location, the pairs were viewed in two combinations (upper and lower combinations) (see Fig. 3). In this text, the upper materials and upper colors are written first (e.g. "fabric + timber" means fabric is on top and timber is on the bottom). Figure 3 shows the layouts of the materials, colors, material pairs, and color pairs. To create three material pairs color was fixed (red), and fabric, timber, and plasterboard were used in the following pairs: fabric and timber, fabric and plasterboard, and timber and plasterboard. The material models were identical except for their material types. To create three color pairs material type was fixed (fabric), and red, white and green were used in the following pairs: red and white, red and green, and white and green. All models, except for their colors, were identical.

Each participant saw only one model (e.g. only fabric material model or only red color model, or only fabric +
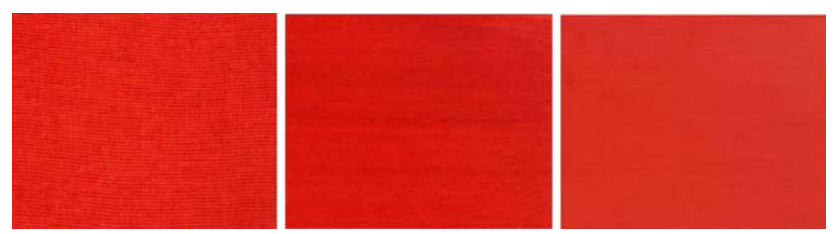

Fig. 7. Surfaces of material models (red fabric, red timber, and red plasterboard, respectively). timber paired materials model in Fig. 3) and answered two open-ended questions. Single materials and single colors for the material pairs and color pairs, respectively, were used to elicit associations about the relationship between single materials or single colors and their respective pairs (see Fig. 3). All models were split horizontally halfway up a wall to better represent commonly encountered interiors in real life, and the same size of surface area was used for each material model and color model.

Materials. The researchers selected three typical interior construction materials: fabric (100\% cotton), timber (laminated veneer board), and plasterboard. These materials are widely used in interiors and they can be modified by water-based protectors and shaped or cut without any loss of identity. Timber dyes cover and change the wood's surface qualities, such a grain, texture, and pattern; however, water-based protectors penetrate the surfaces of timber and fabric, and protect their surface qualities after they were colored. Using protectors, the material type of the models can be properly viewed. Sirca water-based paint was used for the timber and fabric, and Marshall water-based matte indoor wall paint was used for the plasterboard in order to protect their surface qualities and provide visible surface characteristics of each material. Red, with the S 3070-Y90R NCS code, was applied to color the surfaces of fabric, timber, and plasterboard models. NCS color Scan 2.0 was used to determine the paint codes to ensure the identical color for all models after they were colored. All material models were identical in their visual and surface qualities: shape, size, thickness, and color and their material types are visible (see Fig. 7).

A material's reactions to sandpaper and paint determined the type of timber chosen: Fagus-covered laminated veneer board. Hardwood, which has been moistened and straightened, has unpredictable and nonidentical surface qualities after sandpaper and paint processes. Unlike hardwood, fagus-covered laminated veneer boards have less-obvious grains and their surface qualities change less than other timber types. Absorption ability determined the type of fabric: $100 \%$ cotton fabric was preferred to prevent any sparkle from plastic ingredients. Finally, plasterboard was chosen because of its wide range of usage in real-life interiors. Matte paint prevents glare on surfaces (see Fig. 7).

Color. Colors were selected with the natural characteristics of the materials in mind. The researchers used the same colors for all pairs (three material pairs and three color pairs). Because of Timber's limited color
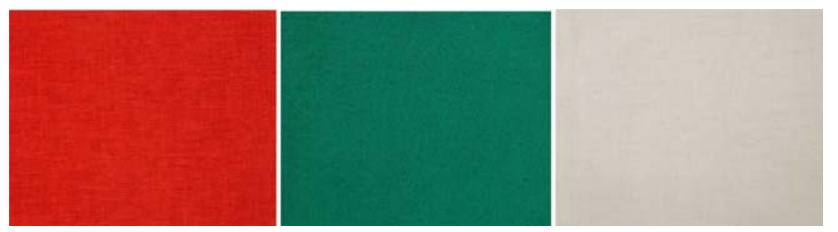

Fig. 8. Surface of color models (red fabric, green fabric, and white fabric, respectively). 
TABLE II. NCS codes, brands, and required proportions of colors.

\begin{tabular}{lllr}
\hline Colors & NCS code of finished surfaces & Brand & Required proportions \\
\hline Red & S 3070-Y90R & Sirca CT5503 & $8.5 / 5$ paint/water \\
Green & S 5040-B80G & Sirca PWN143 & $15 / 5$ paint/water \\
White & S 0510-R50B & Dewilux Eco-Color A-14-1000 & $1 / 0$ paint/water \\
\hline
\end{tabular}

palette, the color chosen for it was the main concern, and determined the color selection for all pairs. Therefore, all colors were first explored with all materials, and the researchers selected three colors from the restricted color ranges of the water-based protector for timber with the NCS 96 Atlas. Timber was the most difficult material on which to produce separate identifiable distinct colors, namely red, green, white, because it has a restricted color palette for water-based paints. These three initial timber colors, which were selected from the Sirca and Dewilux water-based paint color chart for timber, determined the colors of the other two materials. Red (S 3070-Y90R), a powerful and attention-grabbing color for interiors and its afterimage, the complementary color green (S 5040B80G), were selected with white (S 0510-R50B), an achromatic color, because White is the most common achromatic color for interiors (see Fig. 8). The researcher aimed to attain similar saturation and lightness levels for these three colors (red, white, and green) with the limited color palette. The original paints were watered down in order to modify the colors' saturation and lightness levels and ensure similar characteristics (see Table II).

\section{Procedure}

There were two phases to the experiment. First, participants (all of whom were randomly selected) were asked questions about eye and vision deficiencies, performed Ishiara's Color-Blindness Test, and if they passed the test, were accepted for the study (wearing their eye glasses or corrective lenses if they had any eye or vision deficiencies such as astigmatic, myopic, etc.). Next, they received the information form, and if they still wanted to participate in the experiment after reading it, they were asked to fill out and sign the consent form. To begin the experiment, all lighting was turned off except the light in the experiment box. The first phase of the study involved a questionnaire (gender, date of birth, department/profession, and year of study), which was answered under the experiment conditions to provide adaptation time for the participants' eyes.

The second phase of the study began with the presentation of the model. Free associations of each material, color, material pair, and color pair were explored with the same methodology. Participants were not allowed to touch the models before or during the experiment. Interiors as a large-scale product are experienced with five senses, however, vision is the first and dominant sense. For instance, people tend to touch walls or smell indoor environment but each individual with full visual ability firstly and mostly perceives and experiences interiors with their visual sense. The models represented a corner of an ordinary interior, which had no function assigned, and had no door, furniture, window, or any other interior element (see Fig. 9). Participants were accepted individually into the experiment room and sat on the same chair, which was fixed to the floor, to ensure each participant saw the model from the same position. Each model was assessed by at least 15 participants, totalling 192 different participants assessed the models (see Table III).

Participants were informed about the interior that models were represented. They were told to look at the model in the experiment box and imagine it was a corner of an ordinary interior. The first question asked participants to write down five adjectives inspired by the model they observed. There was no time restriction or any other requirement (if the participants wrote verbs, nouns, functions, etc., those words were also accepted). The participants could also write more or fewer than five words if they chose to. In the second question, participants were asked to explain which characteristics of the model inspired them to write down the descriptive words (see Table IV).

\section{RESULTS}

The data was analyzed by NVivo which is a qualitative data analysis software program ${ }^{31}$ and each data set was grouped by word frequency so that the associations of the materials, colors, material pairs, and color pairs in interiors could be elicited with no biases. The results show the free associations and the word groups obtained for each material, color, material pair, and color pair. First, the results were presented as single and paired models in order to demonstrate within pair relationships. Then their overall results were revealed with their descriptor types. The study findings are expected to be beneficial for interior architects, architects, and product designers as well as for researchers in material science and psychology.

\section{Material Models}

Single Material Models. The fabric model was often associated with "soft," "deep," and "intense," whereas the

TABLE IV. The two open-ended questions of the free-association process.

\footnotetext{
1. Please record at least five adjectives that you think describe these two surfaces when you imagine them as an ordinary interior space.

2. Why do you think these two surfaces inspire you to use these adjectives?
} 


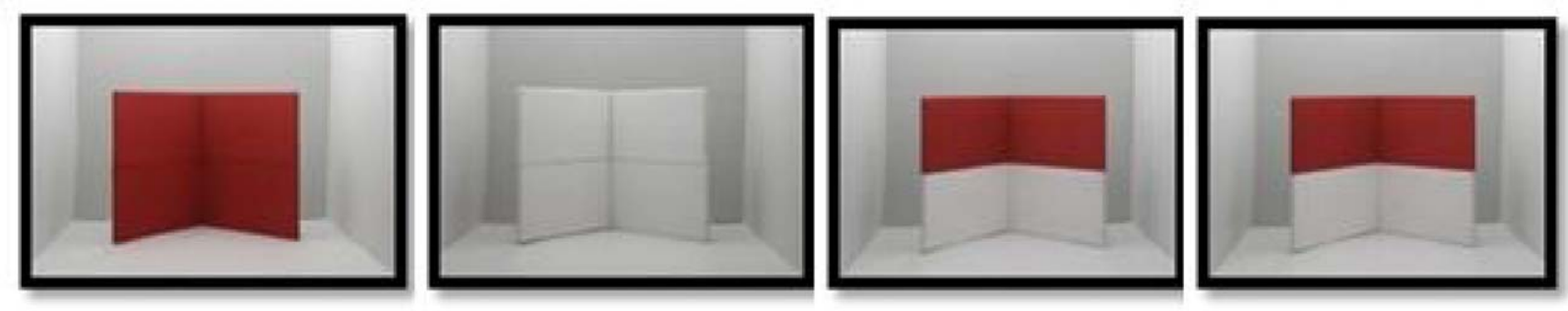

Fig. 9. The red and white fabric models in the experiment box.

timber model was most often associated with "colourful" and "strong." The Plasterboard model most often inspired participants to write down "strong," "red," and "flat" (see Table V).

Paired Materials Models. The fabric and timber paired model was associated with the word "color," "red," and "bright" whereas the fabric and plasterboard paired model were related with "colors," "closed," and "colored." The timber and plasterboard paired model was associated with "color," "rough," and "contrast" (see Table VI).

\section{Color Models}

Single Color Models. The results, showed that participants associated red model with "colorful," "warm," and "strong" in interiors and white model with "clean," "light," and "objective" whereas the green model was related to "calming," "Color," and "soft" (see Table VII).

Paired Colors Models. The red and white paired model inspired the word "clean," "spacious," and "cut" and the red and green paired model was associated with "colorful," "straight," and "contrast." The white and green paired model most often inspired participants to write down "clean," "color," and "interesting" (see Table VIII).

\section{Overall Results}

The researchers classified each adjective with one of the above-noted descriptor types defined in previous research. ${ }^{8}$ In order to embrace all the words elicited in the current study, they utilized similar word groups for this process, in addition to the word itself. For example, "heavy" for the fabric and plasterboard pair, was a sensory descriptor in the previous study. ${ }^{8}$ However, because the participants of the current study could not touch the models and its similar word group includes: deep and dense, this adjective was considered as symbolic descriptor. To provide inter-rater reliability, two more researchers repeated the same procedure that the researchers did

TABLE III. Number of participants.

\begin{tabular}{lclc}
\hline Material models & Participants & Color models & Participants \\
\hline Fabric & 18 & Red & 18 \\
Timber & 17 & Green & 16 \\
Plasterboard & 16 & White & 16 \\
Fabric and Timber & 15 & Red and White & 15 \\
Fabric and Plasterboard & 15 & Red and Green & 15 \\
Timber and Plasterboard & 15 & Green and White & 16 \\
\hline
\end{tabular}

before and assigned three descriptors to the overall results. These researchers are recruited by either Interior Architecture and Environmental Design Department or Architecture Department of the researchers' university and are either native speaker of English or have advanced level English who had lived in USA. Table IX shows the words elicited by each model and their descriptors in the light of this interpretation.

\section{DISCUSSION}

\section{Material Pairs}

The results show that fabric was associated with sensory and affective descriptors such as: deep, intense, and soft. Brown and Farrelly stated that there is a relationship between clothes and interiors since the early era of humankind, which have based on covering (body and interiors) with textiles. ${ }^{11}$ In fact, people tend to dress their environment as they dress their bodies. This study found that for interiors fabric was directly related with emotional terms such as deep and intense. This result might prove that fabric was associated with clothes, therefore, was related to affective descriptors and was perceived as a positive interior design element.

In this study, timber inspired the participants to write down adjectives such as: colorful, strong, comfortable, etc. which are all types of descriptors (see Table IX). In contrast with previous researches, ${ }^{20}$ timber was not directly associated with warm in this study, but was related to home and comfortable, which are not literally but figuratively warm concepts. The participants associated timber with home, comfort, and closed adjectives. As other previous research suggested, ${ }^{21}$ timber was one of the first materials used in human shelters and has been historically associated with home. ${ }^{11}$ Future studies could explore whether timber has these associations across cultures.

The results demonstrate that plasterboard was associated with sensory and symbolic descriptors such as: strong, red, and flat. The participants related firm and smooth surface of the material with the adjectives of strong and flat. The reasons given for the associations prove that people concentrated on color with texture, shape, and angle when it was presented on plasterboard. The results show that plasterboard was associated with more materialistic words than the other materials and that plasterboard alone was not related to any affective adjective. 
TABLE V. NVivo word frequency table of single materials.

\begin{tabular}{|c|c|c|c|c|c|c|c|c|}
\hline \multicolumn{3}{|c|}{ Fabric single material } & \multicolumn{3}{|c|}{ Timber single material } & \multicolumn{3}{|c|}{ Plasterboard single material } \\
\hline Word & Count & Similar words & Word & Count & Similar words & Word & Count & Similar words \\
\hline Soft & 9 & $\begin{array}{l}\text { Small, soft, } \\
\text { dull }\end{array}$ & Colorful & 11 & $\begin{array}{l}\text { Bright, colorful dark, deep, } \\
\text { painted, red }\end{array}$ & Strong & 5 & $\begin{array}{l}\text { Hard, strong, } \\
\text { warm, } \\
\text { powerful }\end{array}$ \\
\hline Deep & 6 & $\begin{array}{l}\text { Broad, deep, } \\
\text { intense, } \\
\text { thick }\end{array}$ & Strong & 7 & haRd, solid, strong, warm & Red & 5 & Red \\
\hline Intense & 6 & $\begin{array}{l}\text { Deep, intense, } \\
\text { sharp, thick }\end{array}$ & Comfortable & 5 & $\begin{array}{l}\text { Calm, comfortable, cozy, } \\
\text { homely, rich }\end{array}$ & Flat & 5 & $\begin{array}{c}\text { Flat, plain, } \\
\text { straight }\end{array}$ \\
\hline Red & 4 & red & Wooden & 5 & Wooden & Square & 4 & $\begin{array}{l}\text { Square, } \\
\text { straight }\end{array}$ \\
\hline Lined & 4 & $\begin{array}{l}\text { Cotton, cross, } \\
\text { lined, rough }\end{array}$ & Closed & 5 & Closed, enclosedwarm & Pointed & 3 & $\begin{array}{l}\text { Corner, } \\
\text { pointed, } \\
\text { sharp }\end{array}$ \\
\hline \multirow[t]{3}{*}{ Rough } & 4 & $\begin{array}{l}\text { Lined, rough, } \\
\text { texture, } \\
\text { textured }\end{array}$ & Pointed & 4 & Deep, high, pointed & & & \\
\hline & & & Homely & & $\begin{array}{l}\text { Comfortable, homely, house, } \\
\text { plain }\end{array}$ & & & \\
\hline & & & Solid & \multirow{2}{*}{\multicolumn{2}{|c|}{$\begin{array}{l}\text { - Material and color } \\
\text { - My associations } \\
\text { - Color and material } \\
\text { - Reminds me-associations } \\
\text { - Solidity and Color } \\
\text { - Connected, space } \\
\text { - angle } \\
\text { - Color } \\
\text { - Color } \\
\text { - Color } \\
\text { - Color } \\
\text { - Color and position } \\
\text { - Barriers } \\
\text { - Color } \\
\text { - Go forward } \\
\text { - Look } \\
\text { - Color }\end{array}$}} & & & \\
\hline Reason & \multicolumn{2}{|c|}{$\begin{array}{l}\text { - Both simple and bold } \\
\text { - Shape, Color, and space } \\
\text { - Simplicity and Color } \\
\text { - Color } \\
\text { - Color and angle } \\
\text { - lighting } \\
\text { - Color } \\
\text { - Color } \\
\text { - Color and light } \\
\text { - Look } \\
\text { - Material and Color } \\
\text { - Form and material } \\
\text { - Surfaces } \\
\text { - Look } \\
\text { - Material, size, Color } \\
\text { - My feelings } \\
\text { - Material }\end{array}$} & Reason & & & Reason & \multicolumn{2}{|c|}{$\begin{array}{l}\text { - Angle, color, and position } \\
\text { - look } \\
\text { - Color } \\
\text { - Color and material } \\
\text { - Color } \\
\text { - Angle and Color } \\
\text { - cultural associations } \\
\text { - Color } \\
\text { - Observing them } \\
\text { - Texture and color } \\
\text { - Right angle shape } \\
\text { - Angular properties } \\
\text { - Color and shape } \\
\text { - Texture }\end{array}$} \\
\hline
\end{tabular}

Plasterboard, as a widely used interior material, has not been investigated as much as timber and fabric. It would be fruitful to study that material in future studies.

The fabric and timber pair was associated with only sensory descriptors, the fabric and plasterboard pair was related to all types of descriptors and the timber and plasterboard pair was associated with sensory and symbolic descriptors. The study reveals that single materials were associated with different descriptors in interiors by themselves, but when they were paired they were associated with fewer affective descriptors. When timber was paired with any material it lost its affective associations, and the pair of plasterboard and fabric had affective associations that plasterboard alone did not have. These results show that plasterboard not only did not arouse affective associations, but also did not affect the pairs in the context of the concept and pairing timber causes a loss of affective associations.

\section{Color Pairs}

According to the previous study, red in interiors was associated mostly with warm. ${ }^{22}$ Similarly, the findings show that people related red in interiors to warm, strong and colorful, which are sensory, symbolic, and affective descriptors. In contrast with previous study, the current study found that in interiors, red was not associated with energetic, disgust, surprise, anger, fear, or sadness. ${ }^{27}$ However, high-quality ${ }^{25}$ and powerfulness ${ }^{27}$ could be aspects of strong, and warm could be an aspect of love, ${ }^{25}$ passionate, enjoyment, and happiness ${ }^{27}$ (see Table X). These differences between previous studies and this study might be due to different methodologies; for example, the earlier studies utilized virtual presentation of interiors or direct questions to probe the concept.

The results demonstrate that white was associated with clean, light, etc. which are sensory and symbolic descriptors, but does not have any affective associations in interiors. In contrast with previous studies, white was not related to low price, low classes, surprise, sadness, anger, boredom, or fear ${ }^{25,27}$ (see Table X). In the context of industrial design, $\mathrm{Na}$ and Suk, suggested that white is regarded as elegant; ${ }^{26}$ however, in this study it was not directly related with elegant but positive terms such as clean and soft. The difference between these two studies might be due to differences of context and scale. Moreover, white was related to clean, light, and bright because Western countries associate white with purity. ${ }^{23}$ 
TABLE VI. NVivo word frequency table of materials pairs.

\begin{tabular}{|c|c|c|c|c|c|c|c|c|}
\hline \multicolumn{3}{|c|}{ Fabric and timber material pair } & \multicolumn{3}{|c|}{ Fabric and plasterboard material pair } & \multicolumn{3}{|c|}{ Timber and plasterboard material pair } \\
\hline Word & Count & Similar words & Word & Count & Similar words & Word & Count & Similar words \\
\hline Color & 9 & $\begin{array}{l}\text { Bright, color, red, } \\
\text { vibrant, crimson }\end{array}$ & Colors & 5 & Bright, red, colors & Color & 7 & $\begin{array}{l}\text { Bright, color, red, } \\
\text { complementary }\end{array}$ \\
\hline Red & 6 & $\begin{array}{l}\text { Bloody, red, } \\
\text { violent, crimson }\end{array}$ & Closed & 5 & Warm, closed & Rough & 5 & Hard, rough \\
\hline Bright & 5 & Bright, happy, silky & Colored & 5 & $\begin{array}{l}\text { Bright, deep, } \\
\text { red, colored }\end{array}$ & Contrast & 3 & $\begin{array}{l}\text { Contrast, contrasts, } \\
\text { different }\end{array}$ \\
\hline $\begin{array}{l}\text { Wood } \\
\text { Texture } \\
\text { ines }\end{array}$ & $\begin{array}{l}3 \\
3 \\
3\end{array}$ & $\begin{array}{l}\text { wood, splinters } \\
\text { rough, texture }\end{array}$ & Heavy & 4 & Deep, dense, heavy & Natural & 3 & Blood, natural \\
\hline Reason & $\begin{array}{l}\text { - Mater } \\
\text { - Look } \\
\text { - Color } \\
\text { - Color } \\
\text { - textur } \\
\text { - contra } \\
\text { - contra } \\
\text { - surfac } \\
\text { - Color } \\
\text { - The u } \\
\text { closin } \\
\text { - See a } \\
\text { - Light } \\
\text { - Color } \\
\text { - Angle } \\
\text { - Mater }\end{array}$ & $\begin{array}{l}\text { ial experience } \\
\text { e and Color } \\
\text { ast (texture) } \\
\text { ast } \\
\text { ces } \\
\text { and angle } \\
\text { vay space is used, } \\
\text { g in, Color } \\
\text { ind feel } \\
\text { experience } \\
\text { and shape } \\
\text { ial and Color }\end{array}$ & Reason & $\begin{array}{l}\text { - Look } \\
\text { - Color } \\
\text { - Color } \\
\text { - Colors and cor } \\
\text { - Best descriptio } \\
\text { - Texture and loc } \\
\text { - Use of materia } \\
\text { - Color and past } \\
\text { - Perception } \\
\text { - Position } \\
\text { - Shape, color, c } \\
\text { - Cognitive proc } \\
\text { - Color and mat }\end{array}$ & $\begin{array}{l}\text { textures } \\
\text { on, and orientation } \\
\text { s }\end{array}$ & Reason & $\begin{array}{l}\text { - Surfa } \\
\text { - Comp } \\
\text { - Color } \\
\text { - Color } \\
\text { - Color } \\
\text { - Color } \\
\text { - Differ } \\
\text { - Look } \\
\text { - Textu } \\
\text { - Light } \\
\text { - Look } \\
\text { - Color } \\
\text { - Surfa } \\
\text { - Differ } \\
\text { - Color }\end{array}$ & $\begin{array}{l}\text { ces } \\
\text { arison } \\
\text { ences } \\
\text { e, color partition } \\
\text { direction } \\
\text { surface texture } \\
\text { ces } \\
\text { ences } \\
\text { and surface }\end{array}$ \\
\hline
\end{tabular}

As the most common color for interior walls, white evokes humble meanings, such as soft, simple, and objective.

The green model was associated with calming, home, color, etc. which are sensory and affective descriptors. These adjectives demonstrate that green had positive associations for the participants, similar to previous studies $^{25,27}$ (see Table X). However, it is not directly related to the adjectives or words of these studies. In contrast with Ou et al., ${ }^{22}$ in this study, green was not associated with cool. Hutchings, explained the special folkloric situation of green in both Ireland and UK. ${ }^{24}$ In this study, it is interesting to note that, the participants were actually living in Belfast (as a UK city, which has close relation with Ireland); they did not relate green to unluckiness but had positive associations in interiors.

TABLE VII. NVivo word frequency table of single colors.

\begin{tabular}{|c|c|c|c|c|c|c|c|c|}
\hline \multicolumn{3}{|c|}{ Red single color } & \multicolumn{3}{|c|}{ White single color } & \multicolumn{3}{|c|}{ Green single color } \\
\hline Word & Count & Similar words & Word & Count & Similar words & Word & Count & Similar words \\
\hline Colorful & 18 & $\begin{array}{l}\text { Bright, Colorful, } \\
\text { material, paint,red, } \\
\text { vibrant, dark }\end{array}$ & Clean & 11 & $\begin{array}{l}\text { Blank, clean, light, } \\
\text { neat, white }\end{array}$ & Calming & 6 & $\begin{array}{l}\text { Calming, gentle, } \\
\text { smooth }\end{array}$ \\
\hline Warm & 11 & Lively, strong, warm & Light & 7 & Bright, light, soft, white & Color & 5 & Bright, Color, green \\
\hline Strong & 6 & $\begin{array}{l}\text { Hard, intense, } \\
\text { powerful, strong }\end{array}$ & Objective & 5 & $\begin{array}{l}\text { Air, clinical, fabric, } \\
\text { straight objective }\end{array}$ & Soft & 4 & Dull, gentle, soft \\
\hline Bright & 5 & Bright, Colorful, happy & Soft & 5 & Light, small, soft & Bright & 4 & Bright, vivid \\
\hline Fabric & 5 & $\begin{array}{l}\text { Fabric, felt, linen, } \\
\text { material }\end{array}$ & Simple & 4 & Plain, simple & Home & 4 & $\begin{array}{l}\text { Comfortable, home, } \\
\text { plain }\end{array}$ \\
\hline $\begin{array}{l}\text { Material } \\
\text { Reason }\end{array}$ & $\begin{array}{l}3 \\
\text { - Color, t } \\
\text { - Color o } \\
\text { - Materia } \\
\text { - Color a } \\
\text { - Surface } \\
\text { - Color } \\
\text { - Texture } \\
\text { - contras } \\
\text { - Color a } \\
\text { - Color c } \\
\text { - Color a } \\
\text { - Color a } \\
\text { - Color a } \\
\text { - Color } \\
\text { - Color }\end{array}$ & $\begin{array}{l}\text { Linen, material, paint } \\
\text { ture, panels, contrast } \\
\text { my living room } \\
\text { and Colors } \\
\text { texture } \\
\text { nd color } \\
\text { Colors and clean lines } \\
\text { design } \\
\text { trast and surface } \\
\text { material } \\
\text { shade } \\
\text { surfaces }\end{array}$ & $\begin{array}{l}\text { Bright } \\
\text { Reason }\end{array}$ & $\begin{aligned} & 3 \\
& \text { - Color, } \\
& \text { - Look } \\
& \text { - Color } \\
& \text { - Color } \\
& \text { - Color } \\
& \text { - Color } \\
& \text { - Detail } \\
& \text { - Color } \\
& \text { - light a } \\
& \text { - imper } \\
& \text { - chara } \\
& \text { - surfac } \\
& \text { - good } \\
& \text { - light a }\end{aligned}$ & $\begin{array}{l}\text { Bright } \\
\text { shape and position } \\
\\
\text { and look } \\
\text { and texture } \\
\text { s and Color } \\
\text { and single texture } \\
\text { and Color } \\
\text { sonal } \\
\text { cteristics } \\
\text { e } \\
\text { condition } \\
\text { ind Color }\end{array}$ & Reason & $\begin{array}{l}\text { - Color } \\
\text { - Look } \\
\text { - Color } \\
\text { - Light } \\
\text { - Mater } \\
\text { - Exper } \\
\text { - Textu } \\
\text { - Color } \\
\text { - View } \\
\text { - Stand } \\
\text { - Textu } \\
\text { - Color } \\
\text { - What } \\
\text { - Shap }\end{array}$ & $\begin{array}{l}\text { and harmony } \\
\text { and surfaces } \\
\text { ial } \\
\text { ience } \\
\text { e and Color } \\
\text { out } \\
\text { e and Color } \\
\text { i see } \\
\text {, material, and style }\end{array}$ \\
\hline
\end{tabular}


TABLE VIII. NVivo word frequency table of color pairs.

\begin{tabular}{|c|c|c|c|c|c|c|c|c|}
\hline \multicolumn{3}{|c|}{ Red and white color pair } & \multicolumn{3}{|c|}{ Red and green color pair } & \multicolumn{3}{|c|}{ White and green color pair } \\
\hline Word & Count & Similar words & Word & Count & Similar words & Word & Count & Similar words \\
\hline Clean & 5 & Clean, white & Colorful & 13 & $\begin{array}{l}\text { Bright, colorful colors, } \\
\text { dark, flag, green, } \\
\text { red, vibrant }\end{array}$ & Clean & 12 & $\begin{array}{l}\text { Clean, clear, neat, } \\
\text { white fresh, light, }\end{array}$ \\
\hline Spacious & 3 & Large, spacious & Straight & 5 & $\begin{array}{l}\text { Square, squarred } \\
\text { straight, vertical }\end{array}$ & Color & 11 & Bright, color, vibrant \\
\hline Cut & 3 & cold, cut, separate & Contrast & 5 & $\begin{array}{l}\text { Contrast, contrasting, } \\
\text { different, lines }\end{array}$ & Interesting & 8 & Color, interesting \\
\hline Separate & 3 & $\begin{array}{l}\text { Cut, separate, } \\
\text { separated }\end{array}$ & Different & 5 & $\begin{array}{l}\text { Contrast, contrasting, } \\
\text { different, unusual }\end{array}$ & Light & 7 & Bright, light, look, soft \\
\hline Colors & 6 & $\begin{array}{l}\text { Bright, colors, red, } \\
\text { tone, white }\end{array}$ & Bright & 4 & Bright, colorfullurid & Plain & 5 & Flat, plain, simple \\
\hline Fresh & 5 & Clean, fresh, warm & & & & & & \\
\hline Clean & 5 & Clean, fresh, white & & & & & & \\
\hline Medical & 4 & block, medical & & & & & & \\
\hline Reason & $\begin{array}{l}\text { - Color } \\
\text { - Color a } \\
\text { - Reminc } \\
\text { - Look } \\
\text { - Color } \\
\text { - Color a } \\
\text { - Color a } \\
\text { - Materia } \\
\text { - Colors } \\
\text { - Colors } \\
\text { - Color a } \\
\text { - Color a } \\
\text { - Easy tc } \\
\text { - Initial t } \\
\text { - Colors }\end{array}$ & $\begin{array}{l}\text { d shape } \\
\text { workspace } \\
\text { d split } \\
\text { d contrast } \\
\text { and contrast of Colors } \\
\text { d position } \\
\text { d material } \\
\text { nterpret } \\
\text { ughts }\end{array}$ & Reason & $\begin{array}{l}\text { - Shap } \\
\text { - Borde } \\
\text { - Mater } \\
\text { - look } \\
\text { - Color } \\
\text { - My p } \\
\text { - surfac } \\
\text { - Color } \\
\text { - Color } \\
\text { - My ey } \\
\text { - look } \\
\text { - Contr } \\
\text { - Color } \\
\text { - Comk } \\
\text { - Color }\end{array}$ & $\begin{array}{l}\text { e and lines } \\
\text { er of colors } \\
\text { rial and color } \\
\text { and size } \\
\text { erception } \\
\text { ces } \\
\text { s } \\
\text { s } \\
\text { xperiences } \\
\text { ast colors } \\
\text { and shape } \\
\text { oination of Colors } \\
\text { s and angles }\end{array}$ & Reason & $\begin{array}{l}\text { - Lines } \\
\text { - Shap } \\
\text { - Lines } \\
\text { - Color } \\
\text { - Textu } \\
\text { - Color } \\
\text { - The Io } \\
\text { - Color } \\
\text { - Color, } \\
\text { - Color } \\
\text { - Color } \\
\text { - Color } \\
\text { - Color }\end{array}$ & $\begin{array}{l}\text { and color } \\
\text { e and color } \\
\text { and color } \\
\text { re and color } \\
\text { matching } \\
\text { pok } \\
\text { texture, and light }\end{array}$ \\
\hline
\end{tabular}

Three color pairs were always associated with all types of descriptors except red and green color pair. The results showed that red and green lost their affective descriptors when paired with each other. Mahnke stated that overstimulation in interiors is unacceptable for occupants. ${ }^{32}$ In this study, red and green color pair might have overstimulation effect and lost their affective descriptors which they had as a single color. Note that white as a single color was not associated with any affective descriptors in contrast to both of its pairs; red and white color pair, and white and green color pair. With this, it is fruitful to reveal that white should be paired with other colors to increase affective arousal in interiors. In addition, white, both as a single color and as a part of a pair, was associated with "clean," showing that adding it to any pair also added the association of "clean" to that pair as well.

\section{CONCLUSION}

Design should promote positive emotions, ${ }^{33}$ enable pleasure and meaning, ${ }^{34}$ and pursuit well-being of user. ${ }^{35}$ Materials and colors have certain associations in interiors and could be utilized to facilitate these features of design. Therefore, the appropriate material and color can improve clients' and users' interior experiences. In this study, the researchers used an experimental setting to investigate the free associations of materials, colors, material pairs and color pairs. In fact, free association, as a method, reveals diverse results for the concept. As single materials, natural materials evoke affective associations; however, artificial ones do not. Timber as a single material has the most diverse associations with all types of adjectives, whereas plasterboard has fewest one. Moreover, paired materials have fewer affective descriptors than single materials. Pairing timber causes a loss of affective associations, however, plasterboard does not affect the pairs in the same context. As a single color, red and green, and as a paired color, red and white color pair and white and green color pair evoke affective descriptors; however, white as a single color does not. Pairing white enriches its pairs' associations and improves its existence in interiors. Clarifying these associations and meanings would be helpful for designers during material and color selection stage of interiors. Based on the results, materials and colors could be chosen to arouse specific associations and meanings, such as "closed" and "heavy" are associated with fabric and plasterboard material pair, "natural" and "contrast" are associated with timber and plasterboard material pair, "fresh" and "medical" are related to red and white color pair, "contrast" and "different" are associated with red and green color pair, and "clean" and "interesting" are related to white and green color pair (see Table IX). By this way, designers are able to use outcomes of the experimental study for real-life implications. It is interesting to note that both white as a single color and plasterboard as a single material were not associated with any affective descriptors. Moreover, both green as a single color and timber as a single material 
TABLE IX. Overall results with their descriptors.

\begin{tabular}{|c|c|c|}
\hline \multicolumn{3}{|c|}{ Materials } \\
\hline Fabric & Timber & Plasterboard \\
\hline $\begin{array}{l}\text { Soft-sensory } \\
\text { Deep-affective } \\
\text { Intense-affective } \\
\text { Smooth-sensory } \\
\text { Red-sensory } \\
\text { Lined-sensory } \\
\text { Rough-sensory }\end{array}$ & $\begin{array}{l}\text { Colorful-sensory } \\
\text { Strong-symbolic } \\
\text { Comfortable-symbolic } \\
\text { Wooden-sensory } \\
\text { Closed-affective } \\
\text { Homely-affective } \\
\text { Solid-sensory } \\
\text { Pointed-symbolic }\end{array}$ & $\begin{array}{l}\text { Strong-symbolic } \\
\text { Red-sensory } \\
\text { Flat-sensory } \\
\text { Square-sensory } \\
\text { Pointed-symbolic }\end{array}$ \\
\hline $\begin{array}{l}\text { Fabric and timber } \\
\text { Color-sensory } \\
\text { Red-sensory } \\
\text { Bright-sensory } \\
\text { Wood-sensory } \\
\text { Texture-sensory } \\
\text { Lines-sensory }\end{array}$ & $\begin{array}{l}\text { Fabric and plasterboard } \\
\text { Colors-sensory } \\
\text { Closed-affective } \\
\text { Colored-sensory } \\
\text { Heavy-symbolic }\end{array}$ & $\begin{array}{l}\text { Timber and plasterboard } \\
\text { Color-sensory } \\
\text { Rough-sensory } \\
\text { Contrast-symbolic } \\
\text { Natural-symbolic }\end{array}$ \\
\hline $\begin{array}{l}\text { Colors } \\
\text { Red } \\
\text { Colorful-sensory } \\
\text { Warm-affective } \\
\text { Strong-symbolic } \\
\text { Bright-sensory } \\
\text { Fabric-sensory } \\
\text { Material-sensory }\end{array}$ & $\begin{array}{l}\text { White } \\
\text { Clean-symbolic } \\
\text { Light-sensory } \\
\text { Objective-symbolic } \\
\text { Soft-sensory } \\
\text { Simple-symbolic } \\
\text { Bright-sensory }\end{array}$ & $\begin{array}{l}\text { Green } \\
\text { Calming-affective } \\
\text { Color-sensory } \\
\text { Bright-sensory } \\
\text { Home-affective } \\
\text { Soft-sensory }\end{array}$ \\
\hline $\begin{array}{l}\text { Red and White } \\
\text { Clean-symbolic } \\
\text { Colors-sensory } \\
\text { Fresh-symbolic } \\
\text { Medical-symbolic } \\
\text { Spacious-affective } \\
\text { Cut-symbolic } \\
\text { Separate-symbolic }\end{array}$ & $\begin{array}{l}\text { Red and Green } \\
\text { Colorful-sensory } \\
\text { Straight-symbolic } \\
\text { Contrast-symbolic } \\
\text { Different-symbolic } \\
\text { Bright-sensory }\end{array}$ & $\begin{array}{l}\text { White and Green } \\
\text { Clean-symbolic } \\
\text { Color-sensory } \\
\text { Interesting-affective } \\
\text { Light-sensory } \\
\text { Plain-affective }\end{array}$ \\
\hline
\end{tabular}

evoked similar meanings such as home; it may be fruitful to probe this relationship further. For each model, the participants indicated which property of the model inspired the adjectives they chose. For all models, color was regarded as the reason more than other properties, such as material, shape, texture, experience, etc. The study shows that materials and color can effectively manipulate a user's experience of interiors, an important finding for designers, architects, builders, and scholars.

Despite meaningful results, participants' citizenship could be a limitation of the study. In this study, all participants were UK citizens living in Belfast. Some physical elements of the country, such as climate, nature, etc., and cultural associations of its people likely impacted the results. For instance, positive associations of green might be a result of both the lush nature of the country and folkloric meanings. Hence, for comparison, the same experiment could be conducted in different countries with different cultural backgrounds. In addition, however, the models represented an interior space, real-life applications of these materials, colors, material pairs and color pairs may have some differences: more or less intense associations and meanings. Nonetheless, these results might lead interior architects, architects, and designers during their

TABLE X. Comparison of overall results with previous studies.

\begin{tabular}{|c|c|c|c|c|}
\hline \multirow[b]{2}{*}{ Color } & \multicolumn{2}{|c|}{ Emotions (adapted from Ref. 27) } & \multirow{2}{*}{$\begin{array}{l}\text { Brand color associations } \\
\text { (adapted from Ref. 25) }\end{array}$} & \multirow{2}{*}{$\begin{array}{l}\text { Results of current } \\
\text { study (adjectives) }\end{array}$} \\
\hline & Positive emotions & Negative emotions & & \\
\hline Red & $\begin{array}{l}\text { Happiness, surprise, } \\
\text { energetic, powerfulness, } \\
\text { enjoyment, passionate }\end{array}$ & Sadness, anger, fear & High quality, love & $\begin{array}{l}\text { Colorful, warm, strong, bright, } \\
\text { fabric, material }\end{array}$ \\
\hline Green & $\begin{array}{l}\text { Happiness, calmness, } \\
\text { peacefulness, } \\
\text { hopefulness, relaxation, } \\
\text { comfort, modernism }\end{array}$ & $\begin{array}{l}\text { Aversion, boredom, } \\
\text { fearfulness, anxiety, } \\
\text { sadness, annoyance, } \\
\text { mystery, neutral, } \\
\text { nonemotional }\end{array}$ & $\begin{array}{l}\text { Sincerity, warmth, } \\
\text { honesty }\end{array}$ & $\begin{array}{l}\text { Clean, light objective, } \\
\text { soft, simple, bright }\end{array}$ \\
\hline White & Surprise & $\begin{array}{l}\text { Sadness, anger, boredom, } \\
\text { fear }\end{array}$ & Low classes, low price & Calming, color, bright, home, soft \\
\hline
\end{tabular}


design process and give an idea that how these interior design elements arouse associations in real life.

In future studies, other material pairs (e.g. plastics, metals or concrete) and color pairs (e.g., blue-orange or yellow-violet) could be investigated, as well as other achromatic colors (black and gray). Combinations of three or more materials and colors could also be explored in future research.

\section{ACKNOWLEDGMENTS}

This experimental research was conducted as a part of Ph.D. thesis of the first author. The authors preferred to exclude acknowledgement section for the double-blind review process.

1. Berger J. Ways of Seeing. UK: Penguin; 2008.

2. MacLeod CM. Half a century of research on the Stroop effect: An integrative review. Psychol Bull 1991;109:163-203.

3. Wastiels L, Schifferstein HNJ, Heylighen A, Wouters I. Relating material experience to technical parameters: A case study on visual and tactile warmth perception of indoor wall materials. Build Environ 2012; 49:359-367.

4. Jackendoff R. The architecture of the linguistic-spatial interface. In: Bloom P, Peterson MA, Nadel L, Garrett MF, editors. Language and Space. Cambridge MA: MIT Press; 1996. p 01-30.

5. Krippendorff K. The Semantic Turn: A New Foundation for Design. Boca Raton FL: CRC Press; 2006.

6. Su L, Yang Z. Designing for emotional satisfaction: An inquiry of passengers' subjective experience on assistive products for train travel. Int J Design Creativity Innov 2015;3:101-123.

7. Ludueña GA, Behzad MD, Gros C. Exploration in free word association networks: Models and experiment. Cognit Process 2013;15:195200.

8. Fenko A, Otten JJ, Schifferstein HNJ. Describing product experience in different languages: The role of sensory modalities. J Pragmatics 2010; 42:3314-3327.

9. Rompay TJL, Ludden GDS. Types of embodiment in design: The embodied foundations of meaning and affect in product design. Int $\mathrm{J}$ Design 2015;9:1-11.

10. Desmet PMA, Hekkert P. Framework of product experience. Int J Design 2007;1:57-66.

11. Brown R, Farrelly L. Materials and Interior Design. London: Laurence King; 2012.

12. Wastiels L, Schifferstein HNJ, Heylighen A, Wouters I. Red or rough, what makes materials warmer? Mater Design 2012;42:441-49.

13. Chen X, Barnes CJ, Childs THC, Henson B, Shao F. Materials' tactile testing and characterisation for consumer products' affective packaging design. Mater Design 2009;30:4299-310.
14. Hekkert P, Karana E. Designing material experience. In: Karana E, Pedgley O, Rognoli V, editors. Materials Experience Fundamentals of Materials and Design. Oxford: Butterworth-Heinemann; 2014. p 3-11.

15. Karana E, Hekkert P, Kandachar P. Meanings of materials through sensorial properties and manufacturing processes. Mater Design 2009;30: 2778-2784.

16. Karana E, Hekker P. User-material-product interrelationships in attributing meanings. Int J Design 2010;4:43-52.

17. Karana E, Hekkert P, Kandachar P. Material considerations in product design: A survey on crucial material aspects used by product designers. Mater Design 2008;29:1081-1089.

18. Schifferstein HNJ, Wastiels L. Sensing materials: Exploring the building blocks for experiential design. In: Karana E, Pedgley O, Rognoli V, editors. Materials Experience Fundamentals of Materials and Design. Oxford: Butterworth-Heinemann; 2014. p 15-26.

19. Wastiels L, Wouters I. Architects' considerations while selecting materials. Mater Design 2012;34:584-593.

20. Farrelly L. Basics Architecture 02: Construction \& Materiality. Muttenz, Switzerland: Ava Publishing; 2009.

21. Gagg R. Basics Interior Architecture 05: Texture+Materials. Muttenz, Switzerland: Ava Publishing; 2012.

22. Ou LC, Luo MR, Woodcook A, Wright AA. Study of color emotion and color preference. Part II: Color emotions for two-color combinations. Color Res Appl 2004;29:292-298.

23. Holtzschue L. Understanding Color: An Introduction for Designers. Hoboken NJ: Wiley; 2006.

24. Hutchings J. Color in folklore and tradition - The principles. Color Res Appl 2004;29:57-66.

25. Seimiene E, Kamarauskaite E. Effect of brand elements on brand personality perception. Proc Soc Behav Sci 2014;156:429-434.

26. Na N, Suk HJ. The emotional characteristics of white for applications of product color design. Int J Design 2014;8:61-70.

27. Helvacioğlu E. Color-Emotion Associations in Interior Spaces (Unpublished doctoral dissertation). Ankara: Bilkent University; 2011.

28. Odabaşıŏglu S, Olguntürk N. Effects of colored lighting on the perception of interior spaces. Perceptual Motor Skills 2015;120:183-201.

29. Rea MS. The IESNA Lighting Handbook: Reference and Application, 9th edition. New York, NY: Illuminating Engineering Society of North America; 2000.

30. Neufert E. Architect's Data, 2nd International English Edition. London: Halsted Press; 1980.

31. Leech NL, Onwuegbuzie AJ. Beyond constant comparison qualitative data analysis: Using NVivo. School Psychol Q 2011;26:70-84.

32. Mahnke FH. Color, Environment \& Human Response. New York: Van Nostrand Reinhold; 1996.

33. Desmet PMA. Faces of product pleasure: 25 Positive emotions in human-product interactions. Int J Design 2012;6:1-29.

34. Hassenzahl M, Eckoldt K, Diefenbach S, Laschke M, Lenz E, Kim J. Designing moments of meaning and pleasure. Experience design and happiness. Int J Design 2013;7:21-31.

35. Desmet PMA, Pohlmeyer AE. Positive design: An introduction to design for subjective well-being. Int J Design 2013;7:5-19. 